\title{
Incidence of Multiple Sclerosis and Related Disorders in Asian Populations of British Columbia
}

\author{
Joshua D. Lee, Colleen Guimond, Irene M. Yee, Carles Vilariño-Güell, \\ Zhi-Ying Wu, Anthony L. Traboulsee, A. Dessa Sadovnick
}

\begin{abstract}
Background: Global variation in the incidence of multiple sclerosis (MS) is generally ascribed to differences in genetic and environmental risk factors. Here we investigate temporal trends in the incidence of MS and related disorders in British Columbia, Canada, from 1986 to 2010, focusing particularly on the Asian ethnic subpopulation. Methods: A longitudinal database was screened to identify newly diagnosed cases of MS and related disorders, including neuromyelitis optica and clinically isolated syndromes. Age-standardized, sex-specific mean annual incidence was calculated for the Asian and non-Asian population of British Columbia for 5-year intervals from 1986 to 2010. Temporal changes and cohort differences in incidence rates and demographic characteristics were evaluated. Results: During this period, the incidence of MS and related disorders in the non-Asian population remained relatively unchanged, from 10.41 (95\% confidence interval [CI]: 9.87-10.97) to 9.91 (95\% CI: 9.46-10.39) per 100,000 ( $p=0.167$ ). In contrast, incidence in the Asian population doubled during the same period. This increase was driven by a precipitous rise in the incidence of MS in females from 0.71 (95\% CI: 0.01-1.50) to 2.08 (95\% CI: 1.43-2.91) per 100,000 ( $\mathrm{p}=0.004)$, including both Canadian-born and immigrant Asians. The incidence of neuromyelitis optica did not change significantly during this period. Conclusions: The incidence of MS may be increasing among females in the Asian ethnic population of British Columbia.
\end{abstract}

RÉSUMÉ: Incidence de la sclérose en plaques et des maladies connexes dans les populations asiatiques de la Colombie Britannique. Contexte: La variation de l'incidence de la sclérose en plaques (SP) à travers le monde est généralement attribuée à des différences dans les facteurs de risque génétiques et environnementaux. Nous avons étudié les tendances temporales de l'incidence de la SP et des maladies connexes en Colombie Britannique, au Canada, de 1986 à 2010, surtout dans les sous-populations asiatiques. Méthode: Nous avons identifié les nouveaux cas de SP et de maladies connexes, dont la névrite optique et les syndromes cliniques isolés, dans une base de données longitudinale. Nous avons calculé l'incidence annuelle moyenne par sexe, standardisée pour l'âge, dans la population asiatique et non asiatique de la Colombie Britannique, par intervalles de 5 ans, de 1986 à 2010 . Nous avons évalué les changements temporaux et les différences de cohortes dans les taux d'incidence ainsi que les caractéristiques démographiques. Résultats: Pendant cette période de temps, l'incidence de la SP et des maladies connexes dans la population non asiatique est demeurée relativement inchangée, soit de 10,41 (intervalle de confiance [IC] à 95\%: 9,87 à 10,97) à 9,91 (IC à 95\%: 9,46 à 10,39) par 100000 (p=0,167) de population. Par contre, l'incidence dans la population asiatique a doublé au cours de la même période. Cette augmentation s'explique par une hausse rapide de l'incidence de la SP chez les femmes, de 0,71 (IC à 95\%: 0,01 à 1,50) à 2,08 (IC de 95\%: 1,43 à 2,91) par 100000 (p=0,004) de population, incluant les Asiatiques nés au Canada et les immigrants. L'incidence de la névrite optique n'a pas changé significativement pendant cette période. Conclusions: Nous estimons que l'incidence de la SP est à la hausse chez les femmes de la population asiatique résidant en Colombie Britannique.

Keywords: Incidence, Multiple sclerosis, Neuromyelitis optica

doi:10.1017/cjn.2015.36

Can J Neurol Sci. 2015; 42: 235-241

Estimates of multiple sclerosis (MS) morbidity are characterized by marked global variation, owing to population and regional differences in genetic and environmental risk or protective factors. ${ }^{1}$ For instance, the prevalence (the proportion of diseased individuals in a population at a specific time) and incidence (the proportion of new cases in an atrisk population during a specific period $)^{2}$ of MS are considerably lower in Asia than in Canada. ${ }^{3}$ Increases in the incidence, prevalence, and female preponderance of MS are now being recognized. ${ }^{4-6}$ These observations have been primarily confined to populations from regions with high MS prevalence, ${ }^{3}$ but recently, similar trends have been reported in traditionally low-risk populations, ${ }^{7,8}$ suggestive of a temporal increase in environmental risk.
British Columbia (BC), Canada is home to an ethnically diverse population and offers a unique opportunity to compare

From the Department of Medical Genetics, University of British Columbia, Vancouver, Canada (JDL, CG, IMY, CV-G, ADS), Department of Neurology and Institute of Neurology, Huashan Hospital, Institutes of Brain Science and State Key Laboratory of Medical Neurobiology, Shanghai Medical College, Fudan University, Shanghai, China (Z-YW), Faculty of Medicine, Division of Neurology, University of British Columbia, Vancouver, Canada (ALT, ADS).

Received August 4, 2014. Final Revisions Submitted December 22, 2014. Correspondence to: A. Dessa Sadovnick, VCHA - UBC Hospital, University of British Columbia, S113-2211 Wesbrook Mall, Vancouver, British Columbia, V6T 2B5, Canada Email: sadovnik@infinet.net 
trends in the incidence of MS and related disorders in subpopulations with disparate baseline risk. Here we report the first systematic investigation of incidence of these disorders in an Asian ethnic subpopulation in Canada.

\section{Materials ANd Methods}

\section{Case Ascertainment and Classification}

Incident cases of MS and related disorders were identified from a longitudinal patient database at the University of British Columbia (UBC) MS Clinic in Vancouver, BC, Canada. For more than 25 years, the UBC MS Clinic was the only major referral centre in $\mathrm{BC}$ for MS and related disorders. It is estimated to have captured approximately $80 \%$ of MS cases in the province ${ }^{9}$ since its inception on October 1, 1980. Demographic and relevant clinical data were extracted from the clinical and genetic databases of the UBC MS Clinic, including standardized patient records for all patient visits to the clinic from January 1, 1986, to December 31, 2010, inclusive. The five-year interval separating the clinic inauguration date and the start of retrospective observation was selected to enable an adequate run-in period covering the clinic's initial years of operation, during which case ascertainment could be allowed to stabilize to its optimal volume.

Patients were categorized as Asian or non-Asian, based on selfreported ethnicity from routinely collected data in the genetics and clinical databases. The Asian cohort consisted of patients who self-identified as having full ancestry (all four grandparents) with ethnic origins in East or Southeast Asia according to the ethnicity classification scheme of Statistics Canada. ${ }^{10}$ All other patients were assigned to the non-Asian population cohort. Individuals with partial Asian ancestry were not analyzed as a separate cohort because of a relative paucity $(n=13)$ of such cases and a lack of available reference (denominator) census data for this heterogeneous at-risk population. Thus, patients with partial Asian ancestry were included in the non-Asian population cohort. For subgroup analysis, the Asian patient cohort was further stratified by birthplace (immigration status) into Canadian-born and immigrant subcohorts. Place of birth and year of immigration to BC were obtained by self-report or manual review of clinical records.

In addition to conventional MS, we included MS-related diagnoses of neuromyelitis optica (NMO) and clinically isolated syndromes suggestive of MS, collectively termed $M S$ and related disorders hereafter. It was necessary to apply this inclusive ascertainment approach in the present study to account for changing practices in the diagnosis and coding of these disorders (all of which have previously been or are currently included in the MS spectrum ${ }^{11,12}$ ) during the study period. However, because the ratio of NMO to MS is substantially greater among Asian patients relative to Caucasians, ${ }^{13}$ we manually reviewed clinical records for all of the Asian patients and stratified the cohort by diagnosis into MS and NMO. We were unable to individually review clinical records for all patients in the non-Asian cohort to enable similar diagnostic classification. However, based on existing literature, ${ }^{14}$ we reasoned that was likely to account for a negligible fraction $(<2 \%)$ of cases in the non-Asian cohort. All other diagnoses (acute disseminated encephalomyelitis, central nervous system vasculitis, ischemia, sarcoidosis, radiologically isolated syndrome, etc.) were excluded from the present analysis.

Incident cases were defined as individuals who received an initial eligible diagnosis at the UBC MS Clinic during the study period. Here, it was necessary to select diagnosis, as opposed to symptom onset, as the incident event because of onset data being unavailable for some cases. To estimate the impact of diagnostic delay, the interval from symptom onset to diagnosis was also determined when onset data were available. Patients who received their initial diagnosis before their first visit to the UBC MS Clinic were excluded from analysis because these cases were considered to be prevalent. Diagnosis was made by MS-specialist neurologists according to accepted diagnostic criteria for probable or definite $\mathrm{MS}^{15-17}$ or NMO. ${ }^{18}$

\section{Reference Population}

Reference BC population denominators for incidence calculations were obtained from quinquennial census data from Statistics Canada for the years 1986, 1991, 1996, 2001, and 2006. ${ }^{19-23}$ Mid-year population estimates were stratified by age $(0-14,15-24,25-44,45-64$, and $\geq 65$ years) and sex. Population data on ethnic origins were similarly obtained from Statistics Canada. The reference population was stratified by ethnic origin into non-Asian and Asian (substratified into Canadian-born and immigrant Asian) cohorts as previously mentioned.

\section{Standardized Incidence Rates}

Annual incidence rates within each cohort were calculated as the number of newly diagnosed cases divided by the mid-year population estimate for each year from 1986 to 2010, stratified by age and sex. All sex-specific annual incidence rates were age-standardized to the 2006 population of Canada by the direct method and five-year mean annual incidence rates were calculated to enable comparison of incidence across cohorts for years during which no incident MS cases were documented. To account for incomplete capture of MS cases in BC through the UBC MS Clinic, all age-standardized incidence rates were scaled by a constant factor (0.80) in both Asian and non-Asian population cohorts, thereby adjusting for previously documented partial ascertainment. 9

\section{Statistical Analyses}

To account for the limited number of events (incident cases), particularly in the Asian cohort, we evaluated population differences in incidence rates with a binomial test that was conditional on the observed number of events. ${ }^{24}$ Normal approximation to the binomial distribution was used when variance in the observed number of events, $v$, was $\geq 5$, whereas an exact binomial test was applied for $v<5$. Confidence intervals (CI) for incidence densities were estimated with a Poisson distribution according to the method of Schoenberg. ${ }^{25}$ We selected these statistical analyses to suit to the relatively uncommon occurrence of MS and related disorders in our study population, thereby obviating concerns of type I error because of small sample sizes. Time variables were compared with a two-tailed t-test and cohort differences in sex ratio were evaluated with a two-tailed Fisher exact test. All statistical analyses were performed using $R$ statistical package for Windows (version 2.15.1, GNU General Public License).

This study was approved by the Clinical Research Ethics Board University at the University of British Columbia. Written informed consent was obtained from all patients who contributed data to the clinical research database used in this study. 
A

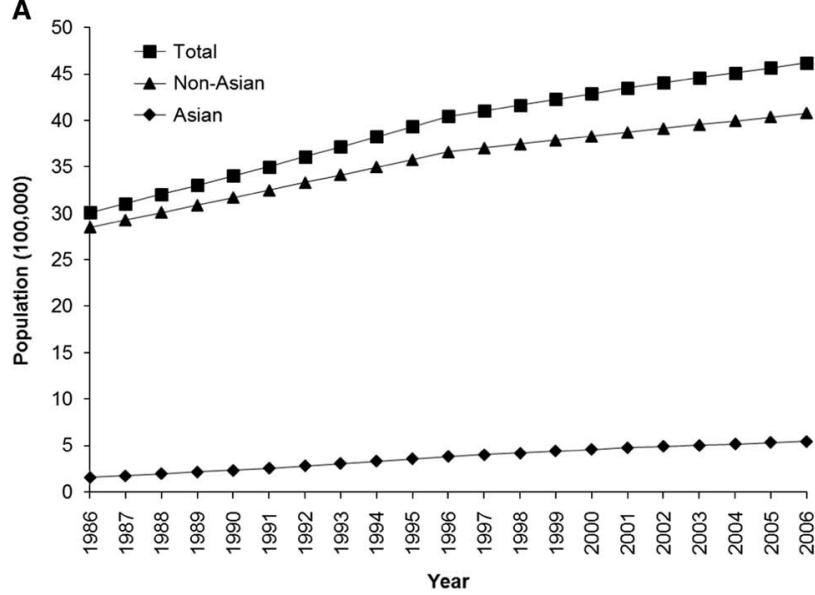

B

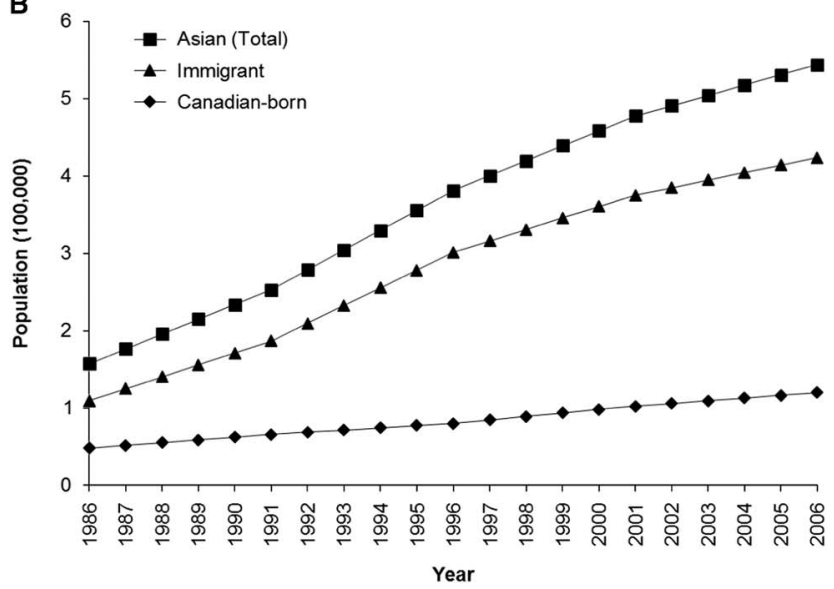

Figure 1: Population growth trends of the (A) total population and (B) Asian ethnic subpopulation of British Columbia, Canada, from 1986 to 2006.

\section{RESUlts}

\section{Reference Population}

Between 1986 and 2006, the BC population grew from 2.85 million to 4.08 million ( $143 \%$ increase). During this period, the Asian subpopulation increased 345\%, from 157,550 to 543,783 (Figure 1A). Rapid expansion of this subpopulation coincided with robust immigration to Canada from East and Southeast Asia, particularly between 1986 through 1995, when the immigrant East/Southeast Asian population in BC increased $254 \%$ (Figure 1B). The modest growth in the non-Asian BC population was consistent with national population growth trends, having increased only $131 \%$ from 2.69 million to 3.53 million.

\section{Patient Demographics}

A total of 8,894 patients seen at the UBC MS Clinic before March 31, 2011, were screened. Of these, 1278 were excluded on the basis of prevalent diagnosis at first clinic visit $(n=87)$, unspecified or ineligible diagnosis $(\mathrm{n}=1191)$, and first diagnosis occurring outside of the study period $(\mathrm{n}=1523)$. Thus, a total of 6093 incident cases were eligible, including 90 Asian cases $(1 \%)$ and 6003 non-Asian cases (99\%). Among Asian cases, 53 (59\%) were diagnosed with MS, 31 (34\%) with NMO, and six (7\%) were clinically isolated syndromes of MS.

Both patient cohorts were characterized by female preponderance (Table 1), which was greater among Asian patients compared with non-Asian patients (female-male sex ratio: 5.4 vs 2.6; $\mathrm{p}=0.012$ ). This disparity was largely driven by a significantly greater female-male ratio in Asian NMO cases (9.3, $\mathrm{p}=0.0256$ ). Although the mean age at symptom onset did not differ significantly between the Asian and non-Asian patient cohorts (33.2 [95\% CI: 30.6-35.8] vs 33.7 [95\% CI: 33.4-34.1] years; $\mathrm{p}=0.685)$, Asian patients were on average younger at diagnosis (37.2 [95\% CI: 34.4-40.0] vs 42.1 [95\% CI: 41.8-42.4] years; $\mathrm{p}=0.001)$. Consequently, the interval from onset to diagnosis was considerably shorter in Asians (4.0 [95\% CI: 2.85.3] years) compared with non-Asians (7.7 [95\% CI: 7.5-8.0] years) $(\mathrm{p}<0.001)($ Table 1$)$.

\section{Incidence of MS and Related Disorders in BC}

The 25-year mean annual incidence of $\mathrm{MS}$ and related disorders in the non-Asian BC population (Figure 2A) was 10.21 (95\% CI: 9.99-10.45) per 100,000, approximately 10-fold greater than in the Asian population (1.02 [95\% CI: 0.85-1.23] per 100,000)

Table 1: Clinical and demographic characteristics of patient cohorts

\begin{tabular}{|c|c|c|c|c|c|}
\hline \multirow[b]{2}{*}{ Diagnosis } & \multirow{2}{*}{$\begin{array}{c}\text { Non-Asian } \\
\text { Total }\end{array}$} & \multicolumn{3}{|c|}{ Asian } & \multirow[t]{2}{*}{$\mathbf{p}^{*}$} \\
\hline & & Total & MS & NMO & \\
\hline Cases, $\mathbf{n}$ & 6,003 & 90 & 53 & 31 & \\
\hline Sex & & & & & 0.012 \\
\hline Female, n (\%) & $4,355(72.5)$ & $76(84.4)$ & $43(81.1)$ & $28(90.3)$ & \\
\hline Male, n (\%) & $1,648(27.5)$ & $14(15.6)$ & $10(18.9)$ & $3(9.7)$ & \\
\hline Female:male ratio & $2: 6$ & $5: 4$ & $4: 3$ & $9: 3$ & \\
\hline \multicolumn{6}{|l|}{ Age } \\
\hline Onset, ${ }^{\dagger}$ mean years $(95 \% \mathrm{CI})$ & $33.7(33.4-34.1)$ & $33.2(30.6-35.8)$ & $31.3(28.0-34.5)$ & $35.2(30.8-39.7)$ & 0.685 \\
\hline Diagnosis, mean years ( $95 \%$ CI) & $42.1(41.8-42.4)$ & $37.2(34.4-40.0)$ & $34.9(31.6-38.2)$ & $40.3(35.2-45.4)$ & 0.001 \\
\hline Diagnostic delay, ${ }^{\dagger}$ mean years $(95 \%$ CI) & $7.7(7.5-8.0)$ & $4.0(2.8-5.3)$ & $3.7(2.3-5.0)$ & $5.2(2.3-8.1)$ & $<0.001$ \\
\hline
\end{tabular}

${ }^{*} \mathrm{p}<0.05$

${ }^{\dagger}$ Clinical onset 

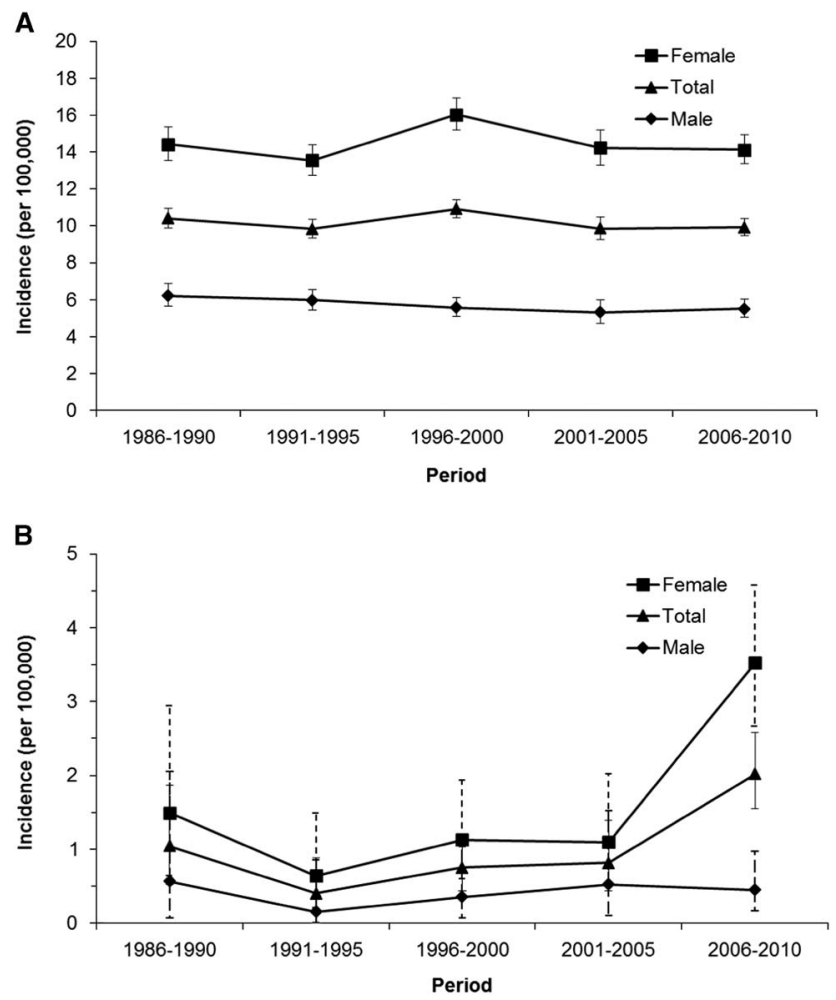

Figure 2: Age-standardized five-year mean annual incidence of multiple sclerosis and related disorders in the (A) non-Asian and (B) Asian subpopulations of British Columbia, Canada, from 1986 to 2010.

$(\mathrm{p}<0.001)$ (Figure 2B). Ethnic group differences in MS incidence trends were underscored by relative stability in the non-Asian population juxtaposed with increasing incidence in the Asian population (Table 2). In the non-Asian population, the incidence of MS and related disorders remained relatively constant between 1986-1990 (10.41 [95\% CI: 9.87-10.97] per 100,000) and 2006-2010 (9.91 [95\% CI:9.46-10.39] per 100,000) $(\mathrm{p}=0.151)$ (Figure 2A, Table 2). In contrast, the mean annual incidence of MS and related disorders doubled in the BC Asian population (Figure 2B, Table 2) from 1.04 (95\% CI:0.52-1.86) per 100,000 to $2.02(95 \%$ CI: $1.55-2.58)$ per $100,000(\mathrm{p}=0.005)$. This precipitous increase was restricted to females.

\section{Incidence of MS and NMO among Asians in BC}

When the Asian cohort was stratified by diagnosis, it was evident that the temporal increase in incidence of MS and related disorders was driven by an increase in incident female MS cases (Figure 3A, Table 3). In this group, incidence increased from 0.71 (95\% CI: $0.23-1.65)$ per 100,000 to 2.08 (95\% CI: $1.43-2.91)$ per 100,000 between 1986 and $2010(\mathrm{p}=0.004)$. In contrast, the incidence of NMO in the Asian subpopulation of BC during the same period was stable (Figure 3B), increasing nonsignificantly from 0.40 (95\% CI: $0.08-1.17$ ) to 0.60 (95\% CI: $0.36-0.95)$ $(\mathrm{p}=0.394)$.

Subgroup analysis following stratification by birthplace revealed a significant increase in MS incidence among females among both Canadian-born and immigrant patients (Table 4). Between 1986 and 2010, the mean annual incidence of MS doubled from 2.43 (95\% CI: $0.50-7.08)$ to 4.97 (95\% CI: $2.57-$ 8.70) per 100,000 in Canadian-born females $(\mathrm{p}=0.003)$ and increased more than sixfold from 0.23 (95\% CI: 0.23-1.27) to 1.49 (95\% CI: 0.92-2.27) per 100,000 in immigrant females $(\mathrm{p}=0.001)$. Between 1986 and 2010, the mean age at migration to Canada among Asian immigrant patients (25.8 years; 95\% CI: 22.3-29.3 years) did not change significantly $(\mathrm{p}=0.203)$.

\section{DISCUSSION}

From the perspective of epidemiological inquiry, $\mathrm{BC}$ is unique in that it is home to both a European ethnic majority population with high MS risk and a large ethnic minority population of East and Southeast Asian extraction with relatively low baseline MS risk. In fact, the latter ethnic group accounted for more than $15 \%$ of the BC population in the 2006 Census of Canada. ${ }^{10,23}$ This is the first study in Canada to evaluate the incidence of MS and related disorders in an Asian ethnic population.

Asian populations are generally regarded as being relatively resistant to MS, presumably because of protective genetic factors or lower environmental risk. In keeping with this paradigm, we observed a tenfold difference in standardized MS incidence in the non-Asian population relative to the Asian population of $\mathrm{BC}$. A recent study in US military veterans reported a considerably smaller disparity in MS incidence between Asian and non-Asian subpopulations in the United States. ${ }^{26}$ Authors of that study reported a threefold difference in age-specific MS incidence in the

Table 2: Age-standardized five-year mean annual incidence of multiple sclerosis and related disorders in Asian and non-Asian subpopulations of British Columbia, Canada, 1986-2010

\begin{tabular}{l|c|c|c|c|c|c}
\hline & \multicolumn{3}{|c|}{ Non-Asian } & \multicolumn{2}{c}{ Asian } \\
\hline Sex & Total & Female & Male & Total & Female & Male \\
\hline $\mathbf{1 9 8 6 - 2 0 1 0}$ & $10.21(9.99-10.45)$ & $14.49(14.11-14.88)$ & $5.75(5.51-6.01)$ & $1.02(0.85-1.23)$ & $1.62(1.31-1.97)$ & $0.40(0.23-0.64)$ \\
\hline $\mathbf{1 9 8 6 - 1 9 9 0}$ & $10.41(9.87-10.97)$ & $14.42(13.56-15.35)$ & $6.21(5.63-6.86)$ & $1.04(0.52-1.86)$ & $1.49(0.64-2.94)$ & $0.57(0.07-2.05)$ \\
\hline $\mathbf{1 9 9 1 - 1 9 9 5}$ & $9.83(9.34-10.35)$ & $13.54(12.74-14.39)$ & $5.97(5.44-6.56)$ & $0.40(0.15-0.88)$ & $0.64(0.21-1.49)$ & $0.15(0.00-0.86)$ \\
\hline $\mathbf{1 9 9 6 - 2 0 0 0}$ & $10.92(10.42-11.44)$ & $16.04(15.20-16.92)$ & $5.58(5.08-6.12)$ & $0.75(0.44-1.20)$ & $1.13(0.60-1.93)$ & $0.35(0.07-1.03)$ \\
\hline $\mathbf{2 0 0 1 - 2 0 0 5}$ & $9.86(9.27-10.49)$ & $14.22(13.29-15.21)$ & $5.32(4.71-6.00)$ & $0.82(0.43-1.39)$ & $1.10(0.53-2.02)$ & $0.52(0.11-1.52)$ \\
\hline $\mathbf{2 0 0 6 - 2 0 1 0}$ & $9.91(9.46-10.39)$ & $14.13(13.37-14.92)$ & $5.52(5.04-6.03)$ & $2.02(1.55-2.58)$ & $3.52(2.67-4.58)$ & $0.45(0.16-0.98)$ \\
\hline
\end{tabular}

Prevalence rates are expressed as cases per 100,000 with $95 \%$ confidence intervals in parentheses. 

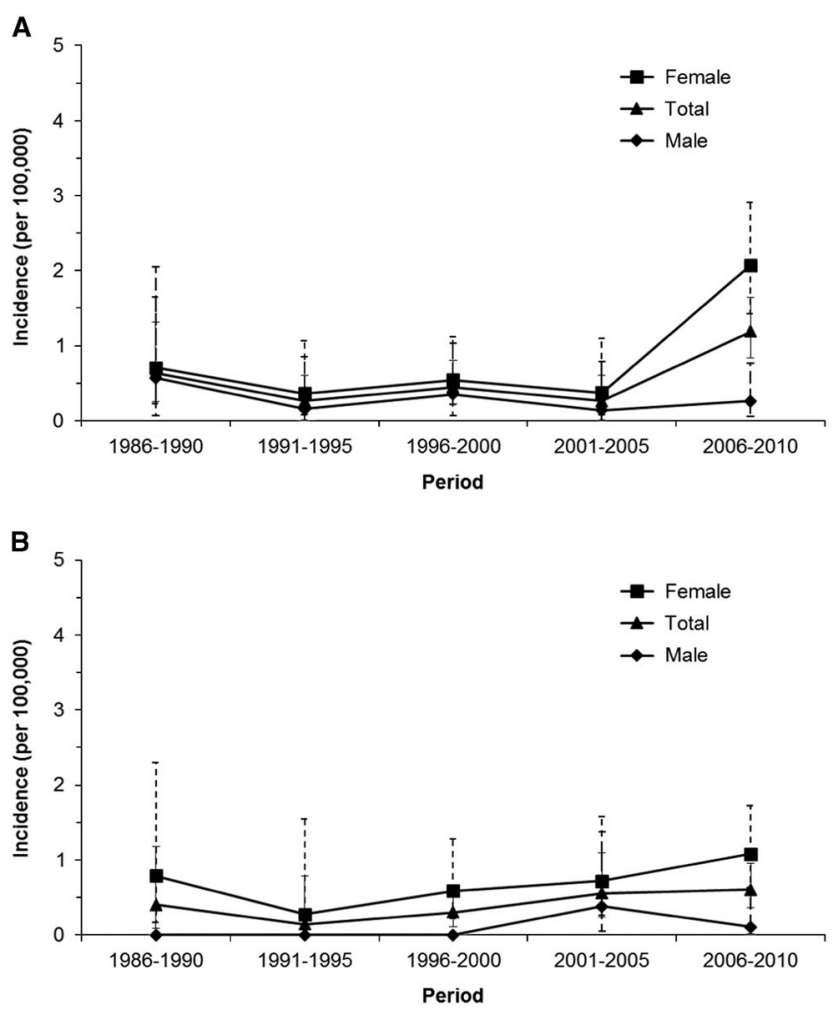

Figure 3: Age-standardized five-year mean annual incidence of (A) multiple sclerosis and $(B)$ neuromyelitis optica in the Asian subpopulation of British Columbia, Canada, from 1986 to 2010.

overall US veteran population compared with personnel who self-identified as Asian or Pacific Islander. Notably, the reported incidence rates among Asians in the US veteran study were remarkably high in general, perhaps on account of the highly selected study population (military personnel), which may in turn explain the discrepant findings.

In the present study, the standardized incidence of MS in Asians was higher than that recently reported in northern Japan, ${ }^{8}$ a region noted for having among the highest MS incidence in Asia. Similar to the Japanese study, we noted increasing MS incidence among females amid relative stability in the rates of NMO. Collectively, these observations imply temporal elevation in MS risk in females in both the Japanese and BC Asian populations.
Given the brevity of this period, constitutional genetic changes can be reasonably ruled out. The authors of the Japanese study previously ascribed these MS epidemiological trends to "westernization" of the Japanese environment, ${ }^{7}$ lucid characterization of which warrants further study.

We questioned whether the increasing incidence of MS in Asians simply reflects advances in case ascertainment in this ethnic population, for instance, from improvements in the sensitivity of diagnosis, increases in referral to MS specialists, or changing patterns in care-seeking among Asians. These explanations, however, do not fully account for the differential trends in incidence because global improvements in MS diagnosis or changes in patterns of referral would reasonably impact observed incidence rates in both Asian and non-Asian subpopulations as well as diagnosis of NMO. Furthermore, the shorter duration and relative temporal stability of diagnostic delay in Asian MS cases challenge the notion that changing patterns or disparities in care-seeking are primarily driving the increase in MS frequency in this population. Increasing MS incidence in Asian immigrants in $\mathrm{BC}$ was concurrent with only modest overall changes in the mean age at migration to Canada over time. Therefore, changing age structure in this subpopulation can also be reasonably ruled out as the primary explanation for the upward trend in MS incidence.

We instead reason that the observed increase in the incidence of MS among Asian females in BC reflects a genuine increase in risk in this subpopulation, potentially as a consequence of an emerging, female-specific environmental risk factor. More specifically, our data suggest that the influence of such a risk factor is largely limited to the Asian subpopulation. Viable candidates to this end include known risk factors for MS, ${ }^{1}$ including vitamin D deficiency and tobacco smoking. It is conceivable these factors would impart differential risk based on ethnic differences in the level of exposure or interaction with genetic factors.

Tobacco smoking in Asian countries, for instance, follows a pattern consistent with our observations, exhibiting increasing use among young adults in Asian populations, particularly in females. $^{27-29}$ If similar trends were present in the BC Asian cohort, smoking behaviour could be one of a number of potentially causative factors. To the best of our knowledge, no Canadian data have been published on smoking among Asians, but a systematic review in the United States found a positive correlation between acculturation and tobacco smoking in AsianAmerican females but not males. ${ }^{30}$

Table 3: Age-standardized five-year mean annual incidence of multiple sclerosis and neuromyelitis optica in the Asian subpopulation of British Columbia, Canada, 1986-2010

\begin{tabular}{|c|c|c|c|c|c|c|}
\hline & \multicolumn{3}{|c|}{ MS, sex } & \multicolumn{3}{|c|}{ NMO, sex } \\
\hline & Total & Female & Male & Total & Female & Male \\
\hline 1986-2010 & $0.59(0.45-0.74)$ & $0.85(0.64-1.11)$ & $0.31(0.16-0.54)$ & $0.39(0.27-0.53)$ & $0.69(0.48-0.96)$ & $0.07(0.01-0.21)$ \\
\hline 1986-1990 & $0.64(0.26-1.32)$ & $0.71(0.23-1.65)$ & $0.57(0.07-2.05)$ & $0.40(0.08-1.17)$ & $0.79(0.16-2.30)$ & 0 \\
\hline 1991-1995 & $0.26(0.08-0.61)$ & $0.36(0.07-1.06)$ & $0.15(0.00-0.86)$ & $0.14(0.00-0.79)$ & $0.28(0.01-1.54)$ & 0 \\
\hline 1996-2000 & $0.45(0.22-0.81)$ & $0.54(0.22-1.12)$ & $0.35(0.07-1.03)$ & $0.30(0.11-0.65)$ & $0.59(0.22-1.28)$ & 0 \\
\hline 2001-2005 & $0.26(0.08-0.61)$ & $0.37(0.08-1.09)$ & $0.14(0.00-0.79)$ & $0.55(0.24-1.09)$ & $0.72(0.26-1.57)$ & $0.38(0.05-1.37)$ \\
\hline 2006-2010 & $1.19(0.84-1.64)$ & $2.08(1.43-2.91)$ & $0.26(0.05-0.77)$ & $0.60(0.36-0.95)$ & $1.08(0.63-1.73)$ & $0.10(0.00-0.58)$ \\
\hline
\end{tabular}

Prevalence rates are expressed as cases per 100,000 with $95 \%$ confidence intervals in parentheses. 
Table 4: Age-standardized five year mean annual incidence of multiple sclerosis and neuromyelitis optica in the Canadian-born and immigrant Asian population of British Columbia, Canada, 1986-2010

\begin{tabular}{l|c|c|c|c|c|c|c|c}
\hline & \multicolumn{4}{|c|}{ Canadian-born } & \multicolumn{4}{c}{ Immigrant } \\
\hline Diagnosis & \multicolumn{2}{|c|}{ MS } & \multicolumn{2}{c|}{ NMO } & \multicolumn{2}{c}{ MS } & \multicolumn{2}{c}{ MMO } \\
\hline Sex & Female & Male & Female & Male & Female & \multicolumn{2}{c}{ Male } & Male \\
\hline $\mathbf{1 9 8 6 - 2 0 1 0}$ & $2.54(1.65-3.76)$ & $0.76(0.25-1.77)$ & $1.58(0.63-3.25)$ & $0.14(0.00-0.79)$ & $0.48(0.32-0.70)$ & $0.27(0.11-0.55)$ & $0.53(0.35-0.77)$ & $0.05(0.01-0.19)$ \\
\hline $\mathbf{1 9 8 6 - 1 9 9 0}$ & $2.43(0.50-7.08)$ & 0 & $2.48(0.06-13.80)$ & 0 & $0.23(0.01-1.27)$ & $0.75(0.09-2.72)$ & $0.41(0.05-1.49)$ & 0 \\
\hline $\mathbf{1 9 9 1 - 1 9 9 5}$ & $1.98(0.41-5.78)$ & $0.56(0.01-3.10)$ & $2.02(0.05-11.27)$ & 0 & 0 & 0 & 0 & 0 \\
\hline $\mathbf{1 9 9 6 - 2 0 0 0}$ & $1.03(0.13-3.73)$ & $2.01(0.05-11.21)$ & 0 & 0 & $0.41(0.13-0.96)$ & $0.25(0.03-0.91)$ & $0.65(0.24-1.41)$ & 0 \\
\hline $\mathbf{2 0 0 1 - 2 0 0 5}$ & $2.16(0.26-7.80)$ & 0 & $1.57(0.19-5.68)$ & $1.08(0.03-6.03)$ & $0.14(0.00-0.79)$ & $0.20(0.00-1.09)$ & $0.53(0.11-1.56)$ & $0.22(0.01-1.25)$ \\
\hline $\mathbf{2 0 0 6 - 2 0 1 0}$ & $4.97(2.57-8.70)$ & $0.93(0.11-3.35)$ & $1.82(0.22-6.58)$ & 0 & $1.49(0.92-2.27)$ & $0.11(0.00-0.59)$ & $1.07(0.60-1.76)$ & $0.11(0.00-0.63)$ \\
\hline
\end{tabular}

Prevalence rates are expressed as cases per 100,000 with $95 \%$ confidence intervals in parentheses.

Vitamin D deficiency is also plausibly implicated as a possible explanation of this trend because it has previously been shown that darker skin pigmentation, such as those in some Asian ethnic groups, is associated with lower serum levels of vitamin D. ${ }^{31}$ In northern latitudes such as BC, excess MS risk associated with vitamin D deficiency would be further amplified for several months in per year by insufficient atmospheric penetration of ultraviolet $\mathrm{B}$ radiation to promote vitamin $\mathrm{D}$ biosynthesis. Asian cultural mores favouring avoidance of sun exposure by females further support this hypothesis. However, the considerable evidence suggesting that the critical window of increased susceptibility to MS resulting from vitamin D deficiency is limited to the prenatal $^{32}$ or early life period ${ }^{33}$ challenges this as the primary explanation for patients who migrated in adulthood.

We present here evidence of an intriguing epidemiological trend, bolstered by a number of methodological strengths. To optimize comprehensive and uniform case ascertainment, we identified cases from the primary clinic for MS and related disorders in BC, using a standardized, longitudinal clinical database. Furthermore, the government-subsidized, universal health care system in Canada, which is accessible to all permanent BC residents irrespective of socioeconomic status, essentially eliminated a major potential source of referral bias. Additionally, appropriately conservative statistical analyses to necessarily account for small sample sizes enabled meaningful interpretation of differential trends in incidence between cohorts of unequal size.

Our findings are suggestive of a female-specific, temporal increase in the risk of MS and related disorders in the BC Asian subpopulation that is more pronounced among immigrants. Evidence for an environmental risk factor that is restricted to a demographically limited subpopulation may have profound implications for disease prevention and understanding etiology because it suggests the existence of an in situ modifiable risk factor. Further work will be needed to understand the identity and biological mechanism of the putative risk factors.

\section{ACKNOWLEDGEMENTS AND Funding}

This study was funded by the Canadian Institutes of Health Research (China-Canada Joint Health Research Initiative [grant number 20R47543]). The authors thank the UBC MS Clinic neurologists for their collective role in the acquisition of clinical data used in this study. The authors are profoundly grateful for the participation of patients of the UBC MS Clinic who have contributed their clinical data to research. The authors acknowledge with gratitude the assistance of K. Atkins, T. Greenwood, M. de Lemos, and E. Dwosh for guidance and advice throughout the preparation of this manuscript.

\section{Disclosures}

JDL received a Multiple Sclerosis Society of Canada Studentship. $\mathrm{CG}$, IMY and Z-YW report no disclosures. CV-G has received research support and is a researcher for Novartis Pharmaceutics. ALT has received grant funding from the MS Society of Canada, Canadian Institute for Health Research, Lotte and John Hecht Foundation, Vancouver Hospital Foundation, Bayer, Roche, Sanofi Genzyme and BiogenIdec; has served on data safety monitoring board for Merck Serono and clinical trial steering committee for Roche; and has received honoraria or travel grants from Biogen Idec, Teva Canada Innovation, Roche, Merck/EMD Serono, Novartis, Medimmune, Sanofi Genzyme, and Chugai Pharmaceuticals. ADS has received grant funding (not for the current study) funds from Biogen Idec, Teva Canada Innovations. Sanofi Genzyme and Novartis.

\section{REFERENCES}

1. Ebers GC. Environmental factors and multiple sclerosis. Lancet Neurol. 2008;7:268-77.

2. Basic statistics: about incidence, prevalence, morbidity, and mortalitystatistics teaching tools. Available from: https://www.health.ny.gov/ diseases/chronic/basicstat.htm. Accessed August 18, 2014.

3. Pugliatti M, Sotgiu S, Rosati G. The worldwide prevalence of multiple sclerosis. Clin Neurol Neurosurg. 2002;104:182-91.

4. Koch-Henriksen N, Sorensen PS. The changing demographic pattern of multiple sclerosis epidemiology. Lancet Neurol. 2010;9: 520-32.

5. Orton SM, Herrera BM, Yee IM, et al. Canadian Collaborative Study Group. Sex ratio of multiple sclerosis in Canada: a longitudinal study. Lancet Neurol. 2006;5:932-6.

6. Koch-Henriksen N, Sorensen PS. Why does the north-south gradient of incidence of multiple sclerosis seem to have disappeared on the northern hemisphere? J Neurol Sci. 2011;311:58-63.

7. Osoegawa M, Kira J, Fukazawa T, et al. Research Committee of Neuroimmunological Diseases. Temporal changes and geographical differences in multiple sclerosis phenotypes in Japanese: nationwide survey results over 30 years. Mult Scler. 2009;15:159-73. 
8. Houzen $\mathrm{H}$, Niino $\mathrm{M}$, Hata $\mathrm{D}$, et al. Increasing prevalence and incidence of multiple sclerosis in northern Japan. Mult Scler. 2008; 14:887-92.

9. Sweeney VP, Sadovnick AD, Brandejs V. Prevalence of multiple sclerosis in British Columbia. Can J Neurol Sci. 1986;13:47-51.

10. Statistics Canada. Ethnic origin and visible minorities, 2006 census. Available from: http://www5.statcan.gc.ca/olc-cel/olc.action? Accessed August 18, 2014.

11. Siva A. The spectrum of multiple sclerosis and treatment decisions. Clin Neurol Neurosurg. 2006;108:333-8.

12. Miller DH, Chard DT, Ciccarelli O. Clinically isolated syndromes. Lancet Neurol. 2012;11:157-69.

13. Kira J. Neuromyelitis optica and Asian phenotype of multiple sclerosis. Ann NY Acad Sci. 2008;1142:58-71.

14. Mealy MA, Wingerchuk DM, Greenberg BM, Levy M. Epidemiology of neuromyelitis optica in the United States: a multicenter analysis. Arch Neurol. 2012;69:1176-80.

15. Poser CM, Paty DW, Scheinberg L, et al. New diagnostic criteria for multiple sclerosis: guidelines for research protocols. Ann Neurol. $1983 ; 13: 227-31$

16. McDonald WI, Compston A, Edan G, et al. Recommended diagnostic criteria for multiple sclerosis: guidelines from the international panel on the diagnosis of multiple sclerosis. Ann Neurol. 2001;50:121-7.

17. Polman $\mathrm{CH}$, Reingold SC, Edan G, et al. Diagnostic criteria for multiple sclerosis: 2005 revisions to the "McDonald criteria". Ann Neurol. 2005;58:840-6.

18. Wingerchuk DM, Lennon VA, Pittock SJ, Lucchinetti CF, Weinshenker BG. Revised diagnostic criteria for neuromyelitis optica. Neurology. 2006;66:1485-9.

19. Statistics Canada. Census of Canada. Public use microdata file on individuals, 1986. 2006. Report No. 216.

20. Statistics Canada. Census of Canada. Public use microdata file. Individuals, 1991. 2006. Report No. 231.
21. Statistics Canada. Census of Canada. Public use microdata file on individuals, 1996. 2006. Report No. 241.

22. Statistics Canada. Census of Canada. Public use microdata file on individuals, 2001. 2005. Report No. 906.

23. Statistics Canada. Census of Canada. Public use microdata file on individuals, 2006. 2006. Report No. 95M0028XVB_F1.

24. Rosner B. Fundamentals of biostatistics, 7th ed. Boston: Cengage Learning; 2010.

25. Schoenberg B. Calculating confidence intervals for rates and ratios: simplified method utilizing tabular values based on the Poisson Distribution. Neuroepidemiology. 1983;2:257-65.

26. Wallin MT, Culpepper WJ, Coffman P, et al. Veterans Affairs Multiple Sclerosis Centres of Excellence Epidemiology Group. The gulf war era multiple sclerosis cohort: age and incidence rates by race, sex and service. Brain. 2012;135:1778-85.

27. Islam MA, Sinha DN, Rinchen S. Social, economic and legal dimensions of tobacco and its control in South-East Asia region. Indian J Public Health. 2011;55:161-8.

28. Lau M, Chen X, Ren Y. Increased risk of cigarette smoking among immigrant children and girls in Hong Kong: an emerging public health issue. J Community Health. 2012;37:144-52.

29. Hong NS, Kim KY, Park SW, et al. Trends in cigarette use behaviors among adolescents by region in Korea. Prev Med Public Health. 2011;44:176-84.

30. Zhang J, Wang Z. Factors associated with smoking in Asian American adults: a systematic review. Nicotine Tob Res. 2008;10:791-801.

31. Clemens TL, Adams JS, Henderson SL, Holick MF. Increased skin pigment reduces the capacity of skin to synthesise vitamin D3. Lancet. 1982;1:74-6.

32. Mirzaei F, Michels KB, Munger K, et al. Gestational vitamin D and the risk of multiple sclerosis in offspring. Ann Neurol. 2011;70:30-40.

33. Munger KL, Chitnis T, Frazier AL, Giovannucci E, Spiegelman D, Ascherio A. Dietary intake of vitamin D during adolescence and risk of multiple sclerosis. J Neurol. 2011;258:479-85. 